\title{
Tricuspid Valve Dilation in a Case of Ostium Secundum Atrial Septal Defect: Therapeutic Dilemmas in the Perioperative Period and a Call for Building the Evidence
}

J Sethumadhavan, H Singh, A Jayant

\begin{abstract}
The adult literature on managing tricuspid regurgitation (TR) in left heart disease is in evolution. Tricuspid valve repair in pediatrics, on the other hand has more or less been restricted to disease subsets, such as children developing TR secondary to right ventricular disease or tricuspid valve anomalies. The pediatric literature on 'acquired' TR [as in congenital heart diseases, such as atrial septal defect (ASD)] is sparse. Some of the concerns that need to be addressed are thresholds for intervention, optimal annular reduction and methods of surgical reduction (DeVega vs ring annuloplasty). We present a case of a 5 years old female child who primarily presented for closure of her ostium secundum ASD. However, intraoperative transesophageal echocardiography (TEE) revealed TR and a tricuspid annular dimension beyond $z+3$ for her size. The surgeon chose to perform a DeVega annuloplasty and both the $A S D$ closure and the annuloplasty were uneventful, postoperative TEE revealed no residual defect, no TR or stenosis. We seek to highlight this case in order to urge a more systematic study of such patients with a local focus since patients in our country present later than usual with asymptomatic heart disease and are more likely to undergo progressive right heart enlargement for a given shunt.
\end{abstract}

Keywords: TEE evaluation of tricuspid valve, TEE measurement of tricuspid annulus, TR in pediatric patients, DeVega in pediatric patients, TEE in congenital heart surgery.

How to cite this article: S ethumadhavan J , Singh $\mathrm{H}$, J ayant A. Tricuspid Valve Dilation in a Case of Ostium Secundum Atrial Septal Defect: Therapeutic Dilemmas in the Perioperative Period and a Call for Building the Evidence. J Perioper Echocardiogr 2013;1(1):24-26.

\section{Source of support $\mathrm{Nil}$}

Conflict of interest: None declared

\section{CASE REPORT}

A 5-year-old girl with a large ostium secundum atrial septal defect (ASD) (transthoracic echocardiographic dimensions of $38 \mathrm{~mm})$, dilated right sided chambers, a $Q_{p} / Q_{s}$ of $2.5: 1$, moderate tricuspid regurgitation (TR), mild mitral regurgitation and mild pulmonary arterial hypertension [right ventricular systolic pressure (RVSP) $=35+$ mean right atrial pressure $\left(R_{A} P_{\text {mean }}\right) \mathrm{mm} \mathrm{Hg}$ ] was referred for ASD closure. Clinical history was significant for recurrent respiratory tract infections alone, biochemistry and hematologic investigations were within normal limits. She weighed $18 \mathrm{~kg}$ and her body surface area was calculated to be $0.74 \mathrm{~kg} \mathrm{~m}^{2}$.
A fter standard induction of anesthesia and endotracheal intubation a pediatric transesophageal echocardiographic probe was inserted and hooked onto the IE 33 M atrix Echocardiography System (Philips, A ndover MA). Transesophageal echo confirmed the preoperative findings, there was no additional ASD, pulmonary venous drainage was normal and the RVSP as obtained from the TR jet was $30+7$ (RAP $_{\text {mean }}$ obtained from central venous catheterization) $\mathrm{mm} \mathrm{Hg}$. The tricuspid annulus was measured in both midesophageal modified bicaval view (Fig. 1) and the transgastric right ventricular inflow-outflow view - it measured $34 \mathrm{~mm}$ in both of these views. TR was deemed mild as evidenced from a vena contracta width of $27 \mathrm{~mm}$.

Cardiopulmonary bypass was instituted with bicaval cannulation with right heart exclusion. Cold blood cardioplegia was used to secure cardioplegic arrest. Foll owing a right atriotomy the echocardiographic findings were confirmed and a valve sizer determined the tricuspid valve to be $35 \mathrm{~mm}$. She underwent Dacron patch closure of the ASD and a DeV ega suture annuloplasty of the tricuspid valve downsized to $28 \mathrm{~mm}$. Postoperative TEE revealed complete closure of the ASD, no tricuspid valve stenosis (Fig. 2) and trivial TR on color Doppler examination (Fig. 3). She made an uneventful postoperative recovery.

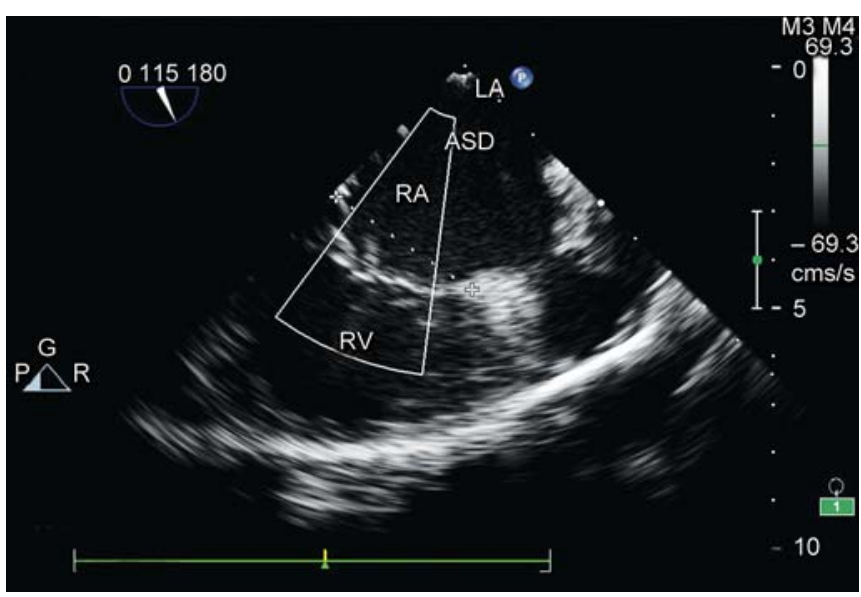

Fig. 1: Measurement of tricuspid annulus in modified bicaval view. LA: Left atrium, ASD: Atrial septal defect, RA: Right atrium, RV: Right ventricle. The annulus measured was $34 \mathrm{~mm}$ in both modified bicaval and transgastric RV in flow-outflow view 


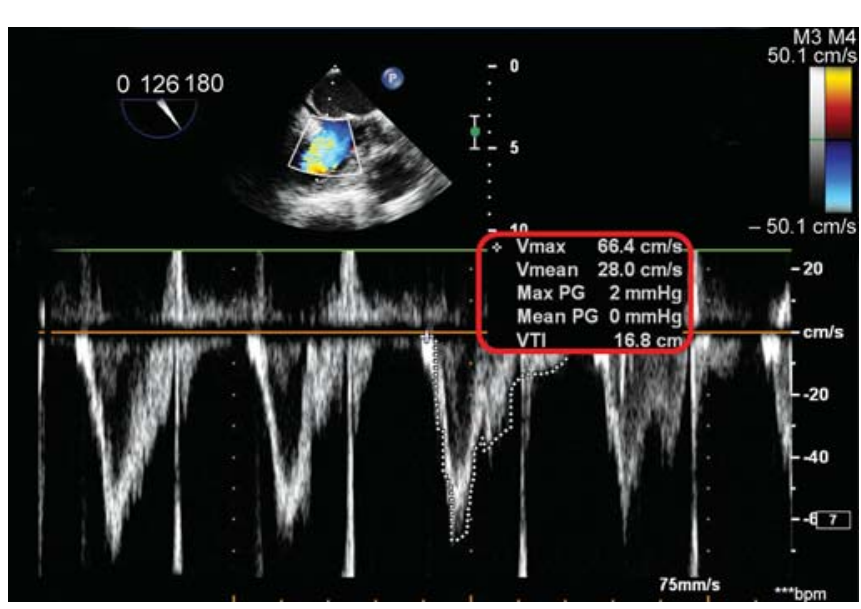

Fig. 2: Measurement of tricuspid inflow velocity in modified bicaval view post correction. The mean gradient was 0 across tricuspid valve

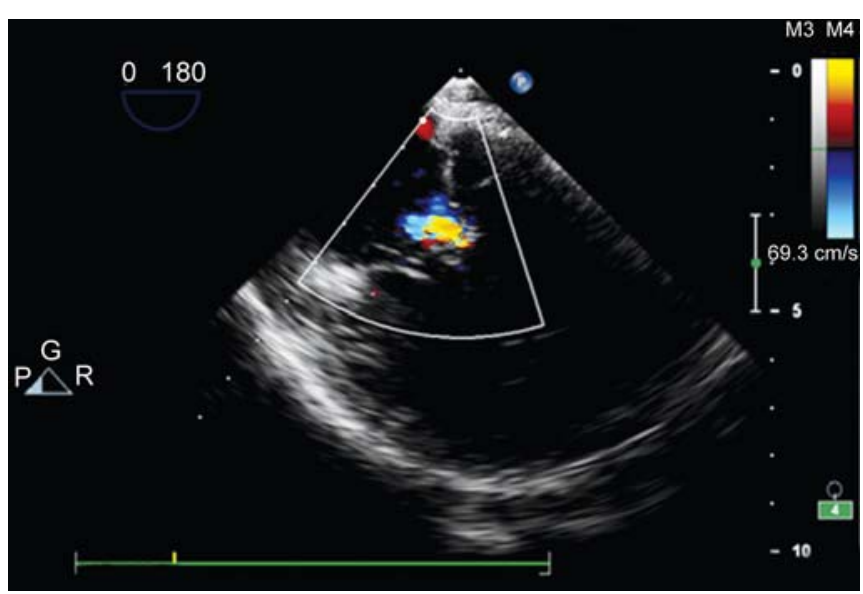

Fig. 3: Vena contracta measured in four chamber view at tricuspid regurgitant jet post TV repair

\section{DISCUSSION}

The natural course of ASDs is considered, on the whole benign. ${ }^{1}$ However, shunting from the left heart to the right actually increases with age. With large nonrestrictive communications the shunt is determined by the relative compliances of the left and right ventricles (RV). While in infancy, shunt fraction is limited by the relatively low compliance of the RV, the shunt increases as the RV becomes more compliant with age even as the left ventricular compliance falls. This sets the stage for dilation of the right side of the heart. In our case, this purportedly is the cause of tricuspid annular dilation. Tricuspid valve repair as an adjunct to uncomplicated ASD closure has scant reportage in the medical literature, tricuspid valve intervention in childhood restricted to special subsets of congenital heart diseases, such as Ebstein's anomaly, ${ }^{2} \mathrm{TR}$ secondary to the $\mathrm{RV}$ exposed to excessive afterload ${ }^{3,4}$ or those with a congenitally deformed valve. ${ }^{5}$

In our approach to this particular patient we decided to size the tricuspid valve given the size of the A SD and the extent of right heart dilation, the right heart diameter as sized on a previously published normogram and based on zscores. ${ }^{6}$ The tricuspid valve was sized in multiple views from both esophageal and gastric windows, ${ }^{7}$ in this particular patient the midesophageal modified bicaval and transgastric RV inflow-outflow view measurements approximated each other.

To determine whether a tricuspid val ve intervention was requi red or not we based therapeutic rationale based on two principles- how much the annular dimension varied from normal and the learning we have, as on date from followup data in left heart disease and 'functional' TR. Falling back on the normogram generated data (vide supra ${ }^{6}$ ) a tricuspid valve dimension of $35 \mathrm{~mm}$ in the indexed patient corresponded to a zscore of $>+3$. This alone, in the absence of mitigating data determined our decision to perform an annuloplasty. Primary congenital abnormalities of the tricuspid valve are considered rare. ${ }^{8}$ When secondary to congenital heart problems this is regarded to occur most often with right sided obstructive lesions. ${ }^{9} \mathrm{D}$ eV ega suture annuloplasty has excellent results in the postoperative follow-up when used in congenital heart disease. ${ }^{10,11}$ Although right ventricular volume overload is underrepresented in these case series it seems reasonable to expect similar outcomes in this subgroup as well. There is some concern that annuloplasty predisposes to tricuspid stenosis, in our patient since the undersizing was to the point of $z+1$ this was not expected and the same was evident in the Doppler interrogation after annul oplasty (Fig. 2). The other concern has been fixing the tricuspid annulus in a growing child potentially risking future tricuspid stenosis; even this has not been usually evident. ${ }^{8}$ In adults, the echocardiographic evaluation of $T R$, especially from the point of evaluation for intervention has undergone continuous refinement, such as the addition of parameters such as tenting area and coaptation depth; ${ }^{12}$ this will undoubtedly be applied to the pediatric subset in time.

In summary, we report the management of tricuspid valve in a patient with a large left to right shunt based on tricuspid valve dimensions based on z scores with good immediate outcome. H owever, one swallow does not make a summer and, in countries like ours where congenital heart disease presentation and intervention occur at later ages than our W estern counterparts this calls for greater preoperative and intraoperative vigilance and acquiring appropriate data sets for planning evidence based surgical protocols.

\section{REFERENCES}

1. Keane JF, Geva T, Fyler DC. A trial septal defect (2nd ed). In: K eane JF, L ock JE, Fyler DC (Eds). Nadas' pediatric cardiology. Philadel phia: Elsevier Inc 2006;603-16. 
2. Boston US, Dearani JA, O' L eary PW, Driscoll DJ, Danielson GK. Tricuspid valve repair for Ebstein's anomaly in young children: A 30-year experience. Ann Thorac Surg 2006;81: 690-96.

3. Hachiro $Y$, Takagi N, Koyanagi $T$, A be T. Reoperation for tricuspid regurgitation after total correction of tetralogy of fallot. A nn Thorac Cardiovasc Surg 2002;8:199-203.

4. U gaki S, K hoo NS, Ross Db, Rebeyka IM, A datia I. Tricuspid valve repair improves early right ventricular and tricuspid valve remodelling in patients with hypoplastic left heart syndrome. J Thorac Cardiovasc Surg 2013 Feb; 145(2):446-50.

5. Reddy VM, M CElhinney DB, Brook M M, Silverman NH, Stanger $\mathrm{P}, \mathrm{H}$ anley $\mathrm{FL}$. Repair of congenital tricuspid valve abnormalities with artificial chordae tendinae. A nn Thorac Surg 1998:66:172-76.

6. Pettersen MD, Wei D, Skeens ME, Humes RA. Regression equations for calculation of z scores of cardiac structures in a large cohort of healthy infants, children and adolescents: A $n$ echocardiographic study. J A m Soc Echocardiogr 2008;21: 922-35.

7. M aslow AD, Schwart $C$, Singh AK . A ssessment of the tricuspid valve: A comparison of four transesophageal windows. J Cardiothorac V asc A nesth 2004;18:719-24.

8. Ootaki $Y, Y$ amaguchi $M, Y$ oshimura N, Oka S, Y oshida M, Hasegawa T. Tricuspid valve repair with papillary muscle shortening for severe tricuspid regurgitation in children. A nn Thorac Surg 2004 Oct; 78(4):1486-88.

9. Kobayashi J, K awashima Y, M atsuda H, Nakano S, M iura T, Tokuan $Y$, et al. Prevalence and risk factors of tricuspid regurgitation after correction of tetralogy of Fallot. J Thorac Cardiovasc Surg 1991;102:611-16.
10. K anter KR, Doelling NR, Fyfe DA, Sharma S, Vincent KH. $\mathrm{DeV}$ ega tricuspid annuloplasty for tricuspid regurgitation in children. A nn Thorac Surg 2001;72:1344-48.

11. M orishita A, K itamura M , N oji S, A omi S, Endo M, K oyanagi $\mathrm{H}$. Long term results after DeV ega's tricuspid annuloplasty. J Cardiovasc Surg (Torino) 2002;43:773-77.

12. Calafiore $A M$, Iaco $A L$, Romeo A, Scandura $S$, Meduri $R$, $V$ arone $E$. Echocardiographic based treatment of tricuspid regurgitation. J Thorac Cardiovasc Surg 2011;142:308-13.

\section{ABOUT THE AUTHORS}

\section{J Sethumadhavan}

Senior Resident, Department of A nesthesia and Intensive Care Postgraduate Institute of M edical Education and R esearch, Chandigarh India

\section{H Singh}

A ssistant Professor, Department of Cardiothoracic and V ascular Surgery, Postgraduate Institute of M edical Education and Research Chandigarh, India

\section{A Jayant (Corresponding Author)}

A ssistant Professor, Department of A nesthesia and Intensive Care Postgraduate Institute of M edical Education and R esearch, Chandigarh India, Phone: +91-172-2756500-01, Fax: +91-172-2744401, 2745078 e-mail: jayant.aveek@gmail.com 